\title{
Implementation of BIM-technologies in the educational program of the architectural university
}

\author{
Alexandr Krivonogov ${ }^{1, *}$, Galina Zakharova ${ }^{2}$, Sergey Kruglikov ${ }^{3}$, and Sergey Plotnikov ${ }^{3}$ \\ ${ }^{1}$ URFU, Institute of Civil Engineering, 620002 Mira str., 19, Ekaterinburg, Russia \\ ${ }^{2}$ USUAA, Department of Applied Informatics, 620075, K. Libknekhta str., 23, Ekaterinburg, Russia \\ ${ }^{3}$ URFU, Graduate School of Economics and Management, 620002 Mira str., 19, Ekaterinburg, Russia
}

\begin{abstract}
BIM-technologies are the dynamically developing trend in a world construction practice. In conditions of a lack of qualified specialists and lack of appropriate educational standards, we offer our practiceoriented methodology for teaching BIM (Building Information Modeling), which is based on the use of new information technologies. Also some projects implemented in BIM and GreenBIM technologies at the Applied Informatics Department are presented.
\end{abstract}

\section{Introduction}

At present, the construction industry is developing very rapidly. In the context of the need for designing in a short time, increasing volumes of project documentation, calculating performance characteristics, interaction of a large number of participants in the life cycle of a construction object, the integrated information model of a building becomes an integral attribute. The BIM-model as an intellectual source of huge amount of interrelated information about the construction object and BIM-technology as a basis for managing this information [1], as well as a platform for interrelations of all specialists in design, construction, operation, reconstruction and demolition processes are confidently entering into the practice of innovative companies in the world of design and construction industry.

Taking into account the experience of such countries as Great Britain, the USA, Singapore, Australia, etc., Russia has become involved in the process of introducing BIMtechnologies into design and construction practice. BIM-technologies are supported at the state level: in 2014 the Ministry of Construction of the Russian Federation issued the decree "On the approval of the plan for the gradual introduction of information modeling technologies in the field of industrial and civil construction". In 2017, the "roadmap" was approved for the implementation of information modeling technologies for buildings at all stages of the life cycle.

The approved document reflects such an important aspect as standardization and provides the development of BIM national standards for the design, construction, operation and demolition phases of buildings, as well as the alignment of normative and technical

\footnotetext{
* Corresponding author: kai5407@gmail.com
} 
documents and estimated standards used in construction in accordance with the classifier of construction resources.

In conditions of the large deficit of qualified personnel, who possess new skills and is able to implement BIM-technologies, the government has an understanding of the need to train specialists to use the information modeling in the field of industrial and civil construction. We need educational standards and new educational programs that meet new requirements.

The system of education, being conservative (or better to say resistant to change), cannot react quickly to such challenges, systematically BIM-technologies in universities are practically not taught. Nevertheless, it seems to us important to find ways to introduce innovative technologies in the educational process for the formation of specialists with new corresponding skills.

In this year, 2017, we have organized and are launching a new educational program in the Urals Federal University "Artificial Intelligence in the Capital Management", where we will teach the newest technologies, including those related to construction projects. Today, investments in new technologies in construction are incredibly small; it is here that the opportunities for a huge economic effect are laid.

Further, taking into account our experience since 2009, when we firstly turned to the BIM, we will refer to the methodology of teaching new technologies and some degree projects carried out under our direction by students of the direction "Applied Informatics in the Architecture" at the Ural State Architectural and Art University.

\section{BIM as a new technology platform}

\subsection{New information technologies in the construction}

Modern information technologies supported by the electronic industry, software, telecommunications, make up the basis of the current techno-economic paradigm. Its scientific basis is achievements in the field of artificial intelligence and interdisciplinary approaches.

New technologies have an impact on all sectors of the economy. World technological trends with great speed are included in all branches of human activity, including in architectural and construction practice. The technology of building information modeling is associated with these innovations and develops in this direction. Let us briefly characterize these innovative technologies.

Cloud technologies. With their application the new concept of Connected BIM was appeared, when all processes, people and technologies are interconnected in the information environment. This technology allows you to manage quickly and efficiently the entire life cycle of the object.

Technologies "smart house" and "smart city". They are also based on cloud services and on the new technology Internet of things (IoT) when all objects (things) we deal with are connected. IoT allows you to organize an independent interconnection of various objects by means of sensors and wireless networks and monitor and control all parameters, for example, in a room to maintain a comfortable environment and to solve many other tasks.

Virtual and augmented reality $(V R / A R)$. 3D visualization of construction objects is carried out in interactive graphics in the real time with immersing a user in a virtual environment with the help of special equipment - glasses or helmets. You can view a building from the outside and inside, have an additional information in the form of the infographic and interact with the environment. 
$3 D$ scanning of the terrain, the combination of data with the GIS system and the formation of a 3D object model in reference to the terrain. The use of unmanned aerial vehicles to obtain current video information about the current state of construction.

$3 D$ printing of buildings, small architectural forms and interior objects. There are examples of printed houses in China, Europe, also in Russia.

Robots programmed for the construction of various structures, for example, "growing" bridges.

Artificial Intelligence. It has unlimited possibilities for solving optimization problems based on machine learning and neural network models and algorithms.

\subsection{BIM evolution}

According to Autodesk, one of the leaders in the software market of BIM, we currently live in the Era of connection (Connected BIM) - these are related BIM processes of information transmission throughout the life cycle of the object. The predecessors are the Era of documentation (AutoCad) and the Era of optimization (Building Information Modeling).

There are also 3 levels of BIM: from the zero level 2D-design, to the first level BIM 3D-models and 2D-drawings. The second level additionally involves the exchange of information in different formats. The third level is an integrated information model of an object in which one change is made for all participants. The latter level is not implemented in any country in the world - for example, in the UK, for the time being implement BIM technology level 2.

The integrated building information model contains a comprehensive description of the facility, ensures the coordinated work of all groups of participants in the development and implementation of the project. The technology allows you to visualize and calculate the future object with the selected materials, have several options with a cost estimate, optimize the constructive part, clean up collisions of engineering equipment and architectural solutions, extract information for compiling a cost estimate for construction, a model for further operation of the facility, which ultimately raises efficiency of the project at all its stages.

Thus, we see that the information model is a multidimensional concept. If it is structured, as for example, in the work on recommendations for the implementation of BIM projects (Pennsylvania University) [2], then a lot of BIM scenarios or as they write BIM Uses are highlighted, these are components of BIM technologies tied to the planning, design, construction and operation stages. There are 25 scenarios at this resource, some of them are: modeling of existing conditions, cost estimation, design, construction analysis, light analysis, energy analysis, mechanical analysis, LEED compliance assessment, compliance, service planning, building system analysis, planning in case of emergency.

To date, this is the mostly complete and up-to-date view on the BIM.

\section{$3 \mathrm{BIM}$ in the educational program}

\subsection{Practical-oriented methods of the teaching}

The Department of the Applied Informatics delivers interdisciplinary specialists in the field "The Applied Informatics" with the profile "The Applied Informatics in the Architecture". We teach students IT-technologies, including relevant sections in such disciplines as "Computer-aided design (CAD)", "The Architectural design", "The Urban ecology", "Environmental factors in the architecture", and many others. We have also developed the system that allows us to comprehensively teach the principles of environmental design and 
building information modeling through the 6 following practice-oriented methods. Some additional information is published in [3, 4].

1. The introduction to the CAD course of modern software tools in the field of BIM and Green BIM such as Autodesk Revit, Graphisoft Archicad. In the Navisworks program, students are introduced to the principles of 4D and 5D-modeling. Autodesk 3DS Max and AutoCAD packages are also used in the learning process. Students are able to import 3D models into the Unity 3D and Unreal Engine software environment to organize interactive project management in the real time for VR. To work with the relief and design of infrastructure objects, AutoCAD Civil 3D is used. The development of project concepts is carried out using the InfraWorks 360 platform. Data bases such as Autodesk's Vault system and CSoft's TDMS system for the cataloging and integration of construction objects and for collective project development were mastered.

2. Discussions of the best world practices in the field of environmental design by the examples of winners of Pritzker and other awards. For interactive lessons students prepare for discussions the topics including the best world examples of «green» architecture [5].

3. Excursions to the objects certified according to the «green» standards in our city and studying the features of the facilities in other regions. We have visited the cottage village Ekodolia near Ekaterinburg to study the experience of building the house of class A+ [6].

4. The cooperation with organizations implementing building automation systems "smart home", the certification systems in according with «green» standards, with experts on energy-efficient housing construction. We regularly invite experts from leading enterprises in the field of energy-efficient housing construction to meet with students, such as the Institute of the Passive House (Moscow), the companies "Teplokrepost" and "Dsystems" (Ekaterinburg), the "Bureau of Engineering" (St.-Petersburg) and many others.

5. The organization of conferences and roundtables with the participation of students and our graduates, the participation in scientific conferences on the introduction of advanced technologies in the urban environment. We also organize the participation of students in scientific and practical seminars organized by companies that produce new materials and technologies ("Knauf", "Izover", "Teplit"), in major international exhibitions and conferences in Ekaterinburg ("Innoprom", "Forum 100+", "City Spot").

6. The participation of students in international and Russian competitions. During several years, students of the department take part in the international competition of the Saint-Gobain company for the design of multi-comfort buildings in different countries. In the Autodesk international competition our student Alexander Ivlev in 2012 received the main prize in the nomination "Give the shape to the future" with the project of an eco-house controlled by the automatic system "Smart House".

\subsection{Examples of diploma projects using Green BIM technologies}

This section includes graduation projects using BIM and Green BIM. These are works related to real objects - industrial, public and residential buildings.

Fig. 1 shows a phased design of innovation Techno Park for manufacture of modular products. It was developed an effective parameterized digital Revit model, parameters determine the behaviour of each element. The result of this technology is significantly increased the design quality and production time of the project.

In the work on the Fig. 2 possibilities and advantages of using BIM technologies in the reconstruction of architectural objects are studied using the example of the residential group in Madrid. This project was presented at the international competition of Saint-Gobain company. BIM is important both for the restoration of historical architecture objects and for planning the reconstruction of objects. 

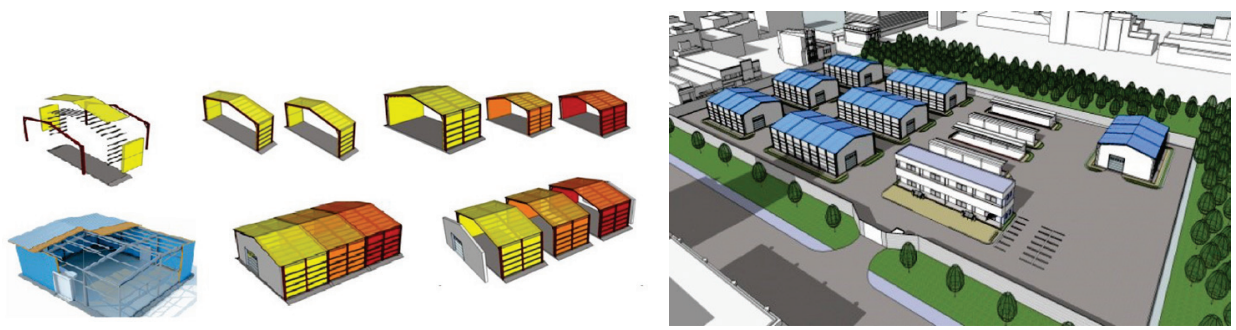

Fig. 1. Stages of designing of innovative Techno Park.

BIM model has all the necessary information. The use of BIM technologies in the reconstruction of buildings is a fairly new and unexplored direction. BIM also allows for designing a reconstruction taking into account new standards for environmental and energysaving requirements.

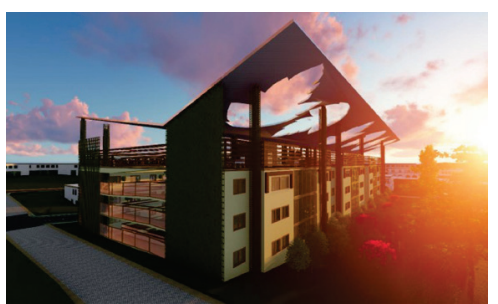

Fig 2. The reconstruction of the residential group in Madrid.
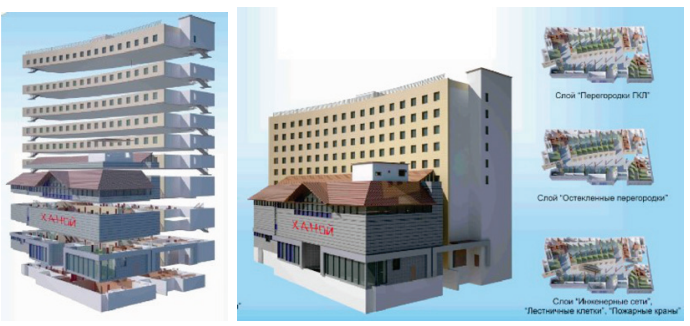

Fig 3. The layer digital model of the trade centre.

On the fig. 3 is the digital model of the trade centre in Ekaterinburg, developed for the Ministry of Emergency Situations to educate members of the organization to rescue operations in case of emergencies. The model allows to disassemble the building in layers and to show all communications.

In the thesis work "The use of energy-efficient standard Green Zoom for design of residential buildings" (fig. 4) the conceptual design of the high-rise apartment building was developed, its evaluation with the Russian system of energy efficiency and sustainability Green Zoom for civil and industrial construction projects has been made.
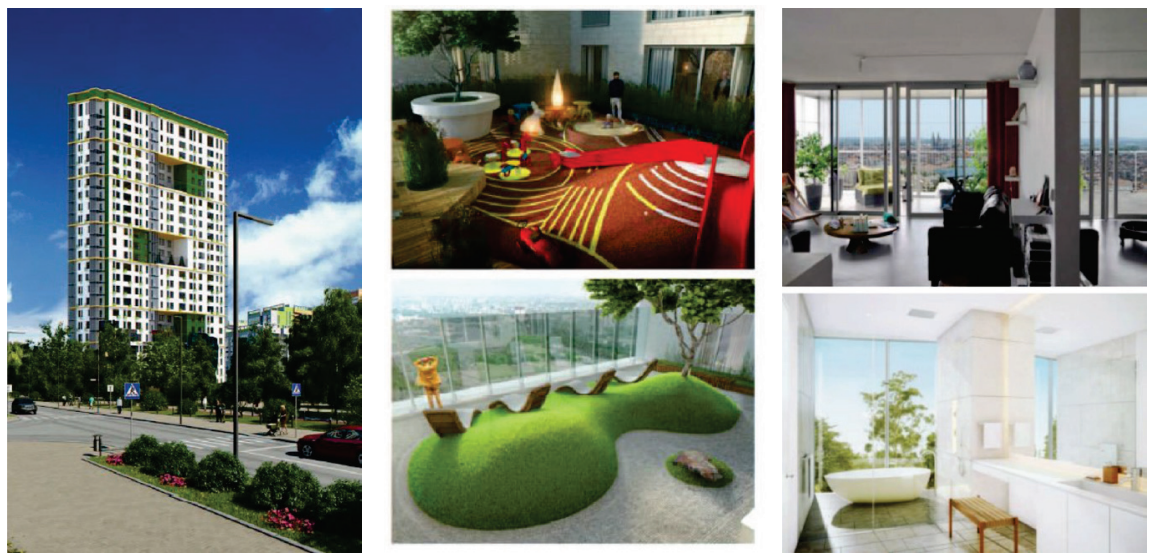

Fig. 4. Visualization of the "green" apartment building. 
The strategic goal of the Green Zoom standard is to create a favourable living environment with affordable and comfortable housing. The evaluation of buildings according the Green Zoom system is carried out at 9 divisions: architectural and planning solutions, the project location and the organization of transport provision, environmental sustainability territory, water efficiency, energy efficiency, reduction of harmful emissions into the atmosphere, environmentally rational choice of building materials and waste control, the ecology of the internal environment of buildings, innovation in design and regional characteristics.

In the Fig. 5 the futuristic project of an individual apartment house, designed to meet the requirements of environmental friendliness and energy efficiency, designed to accommodate the automation system "Smart House" is shown.

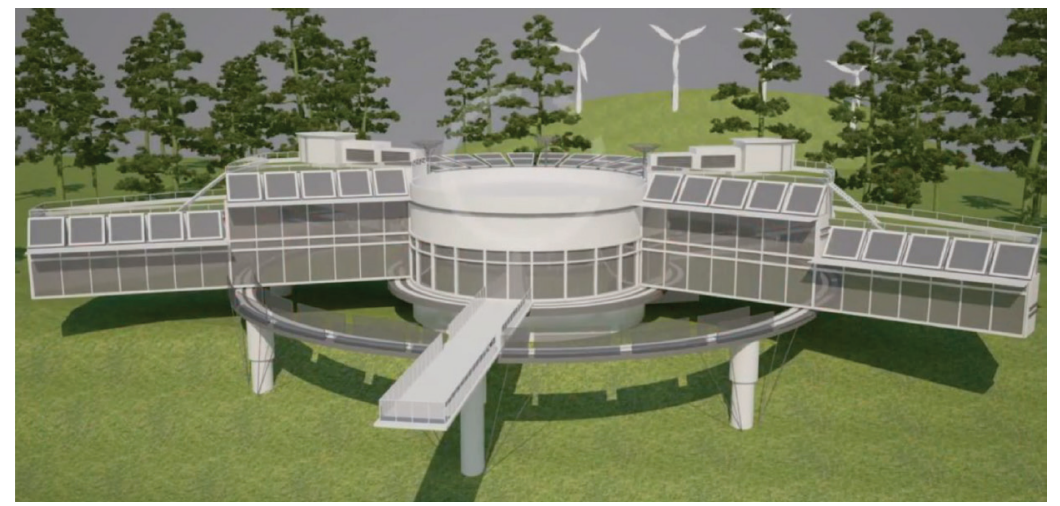

Fig. 5. Visualization of the "green" futuristic smart house.

\section{Conclusion}

Thus, in the article the effective modern technologies in construction industry are presented. The digital modeling of buildings (BIM-technology) and the results of its application in real projects are described.

For more extensive use of the BIM-technology it is necessary to develop educational standards for universities. The department of Applied Informatics in the Ural State University of Architecture and Arts prepares a multi-disciplinary specialists in information technologies in the architecture, and teaches students BIM-technologies. We developed new educational program "Artificial Intelligence in Capital Management" in the Federal University. We also have developed and shortly described here the system that allows us to comprehensively teach the principles of environmental design and information modeling through the practice-oriented methods.

\section{References}

1. V. Talapov. BIM Fundamentals: Introduction to Building Information Modeling (Moscow: DMK, 2011)

2. BIM Project Execution Planning Guide. Available on http://bim.psu.edu/

3. G. Zakharova, A. Krivonogov. Building Information Modeling on the basis of "green" standards for the purpose of sustainable development of territories. Izvestiya Vuzov. Physics (№ 8/2, 37-40, 2016). 
4. G. Zakharova, A. Krivonogov. Necessity of teaching Green BIM technologies in the higher school of the 21st century. II International Conference "Safety Problems of Civil Engineering Critical Infrastructures" (Ekaterinburg, Russia, 116-120, 2016)

5. E. Krygiel, B. Nies. Green BIM: Successful Sustainable Design with Building Information Modeling (Wiley Publishing, 2008, 268 p.).

6. W. Feist. Gestaltungsgrundlagen Passivhäuser (Verlag Das Beispiel, 2000,143 p.) Russian translation: W.Feist. The main provisions on the design of passive houses (Moscow: ACB, 2011, 144 p.). 
